\title{
Citywide Impacts of Cool Roof and Rooftop Solar Photovoltaic Deployment on Near-Surface Air Temperature and Cooling Energy Demand
}

\author{
F. Salamanca ${ }^{1,4} \cdot$ M. Georgescu ${ }^{2,4} \cdot$ A. Mahalov ${ }^{1,3,4}$. \\ M. Moustaoui ${ }^{1,4}$ - A. Martilli ${ }^{5}$
}

Received: 29 June 2015 / Accepted: 5 April 2016 / Published online: 21 April 2016

(C) The Author(s) 2016. This article is published with open access at Springerlink.com

\begin{abstract}
Assessment of mitigation strategies that combat global warming, urban heat islands (UHIs), and urban energy demand can be crucial for urban planners and energy providers, especially for hot, semi-arid urban environments where summertime cooling demands are excessive. Within this context, summertime regional impacts of cool roof and rooftop solar photovoltaic deployment on near-surface air temperature and cooling energy demand are examined for the two major USA cities of Arizona: Phoenix and Tucson. A detailed physics-based parametrization of solar photovoltaic panels is developed and implemented in a multilayer building energy model that is fully coupled to the Weather Research and Forecasting mesoscale numerical model. We conduct a suite of sensitivity experiments (with different coverage rates of cool roof and rooftop solar photovoltaic deployment) for a 10-day clear-sky extreme heat period over the Phoenix and Tucson metropolitan areas at high spatial resolution (1-km horizontal grid spacing). Results show that deployment of cool roofs and rooftop solar photovoltaic panels reduce near-surface air temperature across the diurnal cycle and decrease daily citywide cooling energy demand. During the day, cool roofs are more effective at cooling than rooftop solar photovoltaic systems, but during the night, solar panels are more efficient at reducing the UHI effect. For the maximum coverage rate deployment, cool roofs reduced daily citywide cooling energy demand by 13-14\%, while rooftop solar photovoltaic panels by $8-11 \%$ (without considering the additional savings derived
\end{abstract}

Electronic supplementary material The online version of this article (doi:10.1007/s10546-016-0160-y) contains supplementary material, which is available to authorized users.

$\bowtie$ F. Salamanca

fsalaman@asu.edu

1 School of Mathematical and Statistical Sciences, Arizona State University, PO Box 871804, Tempe, AZ 85287-1804, USA

2 School of Geographical Sciences and Urban Planning, Arizona State University, Tempe, AZ, USA

3 School of Life Sciences, Arizona State University, Tempe, AZ, USA

4 Julie Ann Wrigley Global Institute of Sustainability, Arizona State University, Tempe, AZ, USA

5 Research Center for Energy, Environment, and Technology (CIEMAT), Madrid, Spain 
from their electricity production). The results presented here demonstrate that deployment of both roofing technologies have multiple benefits for the urban environment, while solar photovoltaic panels add additional value because they reduce the dependence on fossil fuel consumption for electricity generation.

Keywords Cooling energy demand $\cdot$ Cool roofs $\cdot$ Rooftop solar photovoltaic panels $\cdot$ Urban climate modelling

\section{List of Symbols}

\begin{tabular}{|c|c|}
\hline$P V$ & Albedo of the upward face of the solar photovoltaic panels \\
\hline$T_{\text {air }}$ & Air temperature $(\mathrm{K})$ above roofs \\
\hline$\varepsilon f f_{P V}$ & Conversion efficiency of the solar photovoltaic panels \\
\hline$L W_{S k v}^{\text {downelling }}$ & Downwelling longwave radiation $\left(\mathrm{W} \mathrm{m}^{-2}\right)$ from the sky \\
\hline$L W_{P V}^{d o w n w e l l i n g}$ & $\begin{array}{l}\text { Downwelling longwave radiation }\left(\mathrm{W} \mathrm{m}^{-2}\right) \text { emitted by the downward face of } \\
\text { the solar photovoltaic panels }\end{array}$ \\
\hline$W_{\text {Roof }}^{\text {downelling }}$ & $\begin{array}{l}\text { Downwelling longwave radiation }\left(\mathrm{W} \mathrm{m}^{-2}\right) \text { reaching a roof covered with } \\
\text { solar panels }\end{array}$ \\
\hline SW $W_{\text {Sky }}^{\text {downelling }}$ & Downwelling shortwave radiation $\left(\mathrm{W} \mathrm{m}^{-2}\right)$ from the sky \\
\hline$S W_{\text {Roof }}^{\text {downelling }}$ & $\begin{array}{l}\text { Downwelling shortwave radiation }\left(\mathrm{W} \mathrm{m}^{-2}\right) \text { reaching a roof covered with } \\
\text { solar panels }\end{array}$ \\
\hline$V$ & Electricity production $\left(\mathrm{W} \mathrm{m}^{-2}\right)$ of the solar photovoltaic panels \\
\hline & Emissivity of the upward face of the solar photovoltaic panels \\
\hline & Fraction of the roof covered by the solar panels \\
\hline & Stefan-Boltzmann constant $\left(\mathrm{W} \mathrm{m}^{-2} \mathrm{~K}^{-4}\right)$ \\
\hline H & $\begin{array}{l}\text { Sensible heat flux }\left(\mathrm{W} \mathrm{m}^{-2}\right) \text { from the solar photovoltaic panels to the } \\
\text { atmosphere }\end{array}$ \\
\hline & Temperature $(\mathrm{K})$ of the upward face of the solar photovoltaic panels \\
\hline$W_{P V}^{\text {upwelling }}$ & $\begin{array}{l}\text { Upwelling longwave radiation }\left(\mathrm{W} \mathrm{m}^{-2}\right) \text { emitted by the upward face of the } \\
\text { solar photovoltaic panels }\end{array}$ \\
\hline upwelling & $\begin{array}{l}\text { Upwelling longwave radiation }\left(\mathrm{W} \mathrm{m}^{-2}\right) \text { emitted by a roof covered with solar } \\
\text { panels }\end{array}$ \\
\hline
\end{tabular}

\section{Introduction}

Many studies reveal that the large-scale deployment of roofing technologies is an effective means of reducing energy consumption (e.g., Akbari et al. 2009; Oleson et al. 2010; Menon et al. 2010; Salamanca et al. 2012a; Cotana et al. 2014; Georgescu et al. 2014). Cool roofs, by virtue of increased reflectivities, absorb less incoming shortwave radiation than dark roofs, thereby promoting a lower skin temperature. As a result, cool roofs reduce heat transfer into the urban environment and into buildings, decreasing near-surface air temperature and cooling energy demand. In wintertime, the potential penalty associated with cool roofs is in general outweighed by the summer benefit and can be annulled if the roofs are typically covered with snow during the cold season (Bretz and Akbari 1997). However, energy savings are more limited for areas that do not have extensive wintertime snow pack, such as the Mid-Atlantic states of the USA (e.g., Georgescu et al. 2014). Various studies have documented the direct 
benefits of large-scale cool roof deployment in urban areas. Performing continental-scale simulations with a regional climate model, Millstein and Menon (2011) reported that nationwide large-scale cool roof deployment for the USA reduce the summertime air temperature by $0.1-0.5^{\circ} \mathrm{C}$ in most urban locations. Similarly, Georgescu et al. $(2012,2013)$ reported that summertime statewide warming due to projected urban expansion for Arizona could be reduced by about $50 \%$ with the complete integration of highly reflective cool roofs. More recently, Li et al. (2014) have evaluated regional impacts of cool and green roof deployment for the Baltimore-Washington (USA) metropolitan area during an extreme heat event. Green roofs can more efficiently partition available energy into latent heat and reduce sensible heat transmission into the urban environment. Although regional differences exist between cool and green roof technologies (e.g., Georgescu et al. 2014), and their assessment must extend beyond the examination of near-surface temperature impacts, this recent work has demonstrated that green roofs (assuming abundant soil moisture) can be nearly as effective as cool roofs at reducing near-surface air temperature.

Roofing technologies, however, are not limited to cool and green roofs. Recent investigations have documented indirect benefits - in addition to the reduction of greenhouse gas emissions-derived from the use of solar photovoltaic systems in urban environments. For example, Dominguez et al. (2011) showed that a building partially covered with solar photovoltaic panels reduces its annual cooling load. Using a simple effective albedo to characterize the efficiency of solar photovoltaic panels, Taha (2013) reported that large-scale rooftop solar panels deployment for the Los Angeles region would not have adverse effects on air temperature and urban heat islands (UHIs). In fact, Taha's simulations (using currently available solar conversion efficiencies) predicted a regional cooling up to $0.2^{\circ} \mathrm{C}$ for the metropolitan area.

Other researchers have utilized more advanced parametrizations of solar systems to evaluate regional impacts of large-scale rooftop solar deployment. For instance, Scherba et al. (2011), using a sophisticated building energy model forced with weather-based datasets, reported that solar photovoltaic arrays (deployed on the top of black roofs) can reduce (on average) the daily sensible heat flux into the urban environment by $11 \%$. On the other hand, Masson et al. (2014), by means of an offline urban canopy model, demonstrated that rooftop solar panels can reduce the near-surface air temperature of Paris, France up to $0.2^{\circ} \mathrm{C}$ during the day, and the UHI intensity (i.e., the 2-m air temperature difference between the warmest urban zone and its surrounding rural neighbourhoods) up to $0.3^{\circ} \mathrm{C}$ during the night under the assumption of a practical deployment scenario (in this hypothetical situation approximately $50 \%$ of each roof was covered with solar panels).

Previous work has provided important insights into potential benefits of rooftop solar arrays. In addition to electricity generation, rooftop solar panels provide further benefits via reduction of the near-surface air temperature. However, in order to provide more realistically quantitative and practical guidance to policy makers and urban planners, such research requires a fully dynamic (i.e., interactive) coupling between solar panels arrays within a building energy model with the outdoor environment.

Here, we thus evaluate (for the first time to our knowledge) regional impacts of largescale cool roof and rooftop solar photovoltaic deployment on near-surface air temperature and citywide cooling energy demand using a fully coupled modelling system composed of a regional climate model and a building energy model that is interactive with the outdoor environment. Specifically, we characterize the diurnal cycle of near-surface air temperature and citywide air-conditioning electricity consumption for different coverage rates of largescale cool roof and rooftop solar photovoltaic deployment for the two major USA cities of Arizona: Phoenix and Tucson. Both Phoenix and Tucson exhibit an intense nocturnal UHI, 
but during the day, they can show oasis effect (e.g., Brazel et al. 2000; Georgescu et al. 2011). The outline of the article is as follows: methodology and numerical experiments are described in Sect. 2. The discussion of the results is presented in Sect. 3, and conclusions and suggestions for future research are presented in Sect. 4.

\section{Methodology}

We use the non-hydrostatic (V3.4.1) version of the Weather Research and Forecasting (WRF) model (Skamarock et al. 2008) coupled to the multilayer building energy (BEP+BEM) system (Salamanca et al. 2011) to characterize the diurnal cycle of near-surface air temperature and citywide air-conditioning electricity consumption (herein near-surface air temperature refers to the 2-m air temperature above ground level). The Noah land-surface model (Chen and Dudhia 2001; Ek et al. 2003) was applied to the fraction of grid cells with natural cover and the multilayer building energy model to the fraction with built cover. The BEP+BEM system is a building energy model (BEM; Salamanca et al. 2010; Salamanca and Martilli 2010) integrated into a multilayer building effect parametrization (BEP; Martilli et al. 2002) that computes heat exchange between the buildings and the outdoor environment as well as the anthropogenic heating due to air-conditioning systems (Salamanca et al. 2012b, 2014, 2015; Martilli 2014; Chow et al. 2014). The BEP+BEM system's ability to reproduce the observed diurnal cycle of near-surface variables (air temperature, wind speed, and wind direction) and citywide air-conditioning electricity consumption has been demonstrated on several occasions (specifically, during several recent extreme heat events including that analyzed here) for the Phoenix metropolitan area (Salamanca et al. 2013, 2014). The excellent agreement obtained in these two previous studies provides confidence in assessing regional impacts of large-scale cool roof and rooftop solar photovoltaic deployment.

\subsection{Parametrization of Rooftop Solar Photovoltaic Panels}

The parametrization adopted here, to characterize solar photovoltaic arrays in the multilayer BEM, is based on the scheme proposed by Masson et al. (2014). In Masson's scheme, solar panels are assumed to be horizontal to avoid unnecessary complexities and details of individual buildings. Here, the same assumption is adopted, and solar panels are assumed to be parallel (or almost parallel) to the roofs. The sensible heat flux from a rooftop solar photovoltaic panel to the atmosphere (term $H$ in Eq. 1 below) is computed as the residual term of the following energy balance equation,

$$
\begin{gathered}
\left(1-\alpha_{P V}\right) S W_{\text {Sky }}^{\text {downelling }}+L W_{\text {Sky }}^{\text {downelling }}-L W_{P V}^{\text {upwelling }}+L W_{\text {Roof }}^{\text {upwelling }} \\
-L W_{P V}^{\text {downwelling }}=E_{P V}+H,
\end{gathered}
$$

where the left-hand side represents the net all-wave radiative flux $\left(\mathrm{W} \mathrm{m}^{-2}\right)$ gained by the solar panel and the term $E_{P V}$ represents its electricity production (for a complete description of symbols used see the List of Symbols). The first term (on the left-hand side) is the net shortwave radiation gained by the upward face of the solar panel, the second and third terms are the net longwave radiation, and finally the fourth and fifth terms represent the net longwave radiation gained by the downward face of the solar panel. The upward longwave radiation from a solar panel is computed as $L W_{P V}^{\text {upwelling }}=\varepsilon_{P V} \sigma T_{P V}^{4}+\left(1-\varepsilon_{P V}\right) L W_{S k y}^{\text {downelling }}$, and the downward longwave radiation emitted by the solar panel to the roof as $L W_{P V}^{\text {downelling }}=\sigma T_{\text {air }}^{4}$ 
(under the hypothesis that the temperature of the downward face is always approximately equal to the air temperature above the roof). Finally, the surface temperature of the upward face is parametrized as $T_{P V}=T_{a i r}+0.05 S W_{S k y}^{\text {downelling }}$, and the electricity production as $E_{P V}=\varepsilon f f_{P V} S W_{S k y}^{\text {downelling }} \min \left[1 ; 1-0.005\left(T_{P V}-298.15\right)\right]$ to take into account that solar photovoltaic panels are more efficient at $25^{\circ} \mathrm{C}$ than at higher temperatures (for more details see Masson et al. 2014).

We assume that the shadowed area of a roof partially covered with solar panels is equal to the surface area of the solar photovoltaic arrays and, as a result, the radiative contributions to the surface energy balance of the roof have been modified as follows,

$$
S W_{\text {Roof }}^{\text {downelling }}=\left(1-f_{P V}\right) S W_{\text {Sky }}^{\text {downelling }},
$$

for the shortwave component and

$$
L W_{\text {Roof }}^{\text {downelling }}=\left(1-f_{P V}\right) L W_{S k y}^{\text {downwelling }}+f_{P V} L W_{P V}^{\text {downwelling }},
$$

for the longwave component, where $f_{P V}$ is the fraction of the roof covered by the solar panels. In the BEP+BEM system, a single temperature is still computed for the roof, and no distinction is made between the parts under or adjacent to the solar panels. However, in order to take into account the effect of solar panels, the total sensible heat flux from a roof to the atmosphere is weight-averaged considering both contributions; the contribution from the solar photovoltaic panels (term $H$ in Eq. 1) and the contribution from the rest of the roof (i.e, the fraction of the roof without solar panels).

\subsection{Numerical Experiments}

We conduct 12 high resolution WRF model experiments, each one covering the same 10-day clear-sky extreme heat period from July 10 (0000 LT) to July 19 (2300 LT) 2009 to assess regional impacts of large-scale cool roof and rooftop solar photovoltaic deployment on nearsurface air temperature and cooling energy demand. The same period has been extensively evaluated against observations for air temperature, wind speed, and wind direction for the Phoenix metropolitan area (Salamanca et al. 2013, 2014), but now we further include the Tucson metropolitan area for the assessment of the model performance (see Sect. 3). All WRF model experiments were initiated $7 \mathrm{~h}$ prior [i.e., July 10 (0000 UTC)], and this time interval was considered as the model spin-up period. Previous WRF model simulations (Salamanca et al. 2015) used identical set-up (including the same horizontal grid domains) and thus only the main points of the model configuration are described here. The horizontal domain was composed of four two-way nested domains with $135 \times 115$ (domain 1), $201 \times 183$ (domain 2), $390 \times 321$ (domain 3), and $615 \times 555$ (innermost domain) grid points, with spatial resolutions of 27, 9, 3, and $1 \mathrm{~km}$, respectively (Fig. 1a). The inner domain covers almost the entire state of Arizona, and includes both Phoenix and Tucson metropolitan regions. All WRF model experiments were conducted with initial and boundary conditions obtained from the National Centers for Environmental Prediction Final Analysis data (number ds083.2) with a grid spacing of $1^{\circ} \times 1^{\circ}$ and a temporal resolution of $6 \mathrm{~h}$. The urban landscape was characterized using the US Geological Survey 30-m 2006 National Land Cover dataset (Fry 2011) in the inner domain (Fig. 1b, c). For the non-urban part, land-use categories were implemented using the MODIS satellite land-cover classification. Building morphological characteristics and thermal properties for roofs, roads, and vertical walls were obtained from Burian et al. (2002) and Clarke et al. (1991), and are detailed in Salamanca et al. (2013, 2014, 2015). During the 10-day extreme heat period it was assumed that every building made use 
(a)

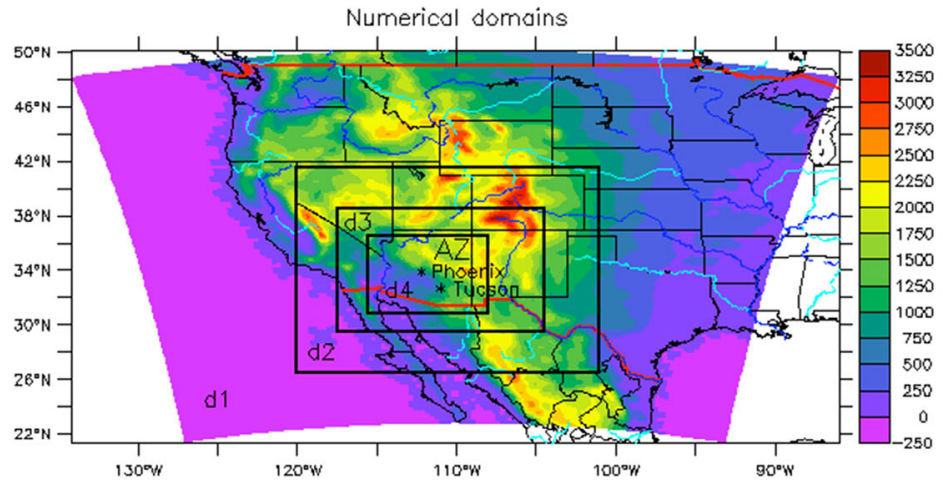

(b)

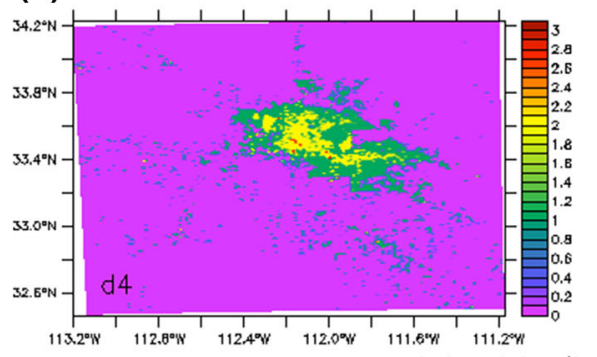

(c)

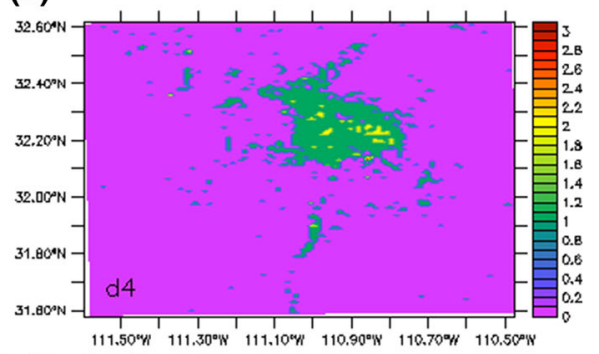

1: Low Intensity Residential (Green)

2: High Intensity Residential (Yellow)

3: Commercial or Industrial (Red)

Fig. 1 a The four two-way nested domains used within WRF model experiments. Terrain height is plotted at intervals of $250 \mathrm{~m}$. b Urban classification based on Fry (2011) for the Phoenix metropolitan area. c Same as in (b) but for the Tucson metropolitan area

of air-conditioning systems and the resulting anthropogenic heat was rejected as sensible heat into the urban environment. This assumption is fully justified because air-conditioning systems that reject latent heat into the urban environment are commonly installed in large buildings in commercial areas and these areas (based on Fry 2011) cover less than $1 \%$ of the current urban landscape in Arizona. However, for cities with extensive commercial areas (e.g., New York City) the effect of latent heat release can be significant (Gutierrez et al. 2015). The Phoenix and Tucson metropolitan areas experience harsh summertime conditions and because daytime maximum near-surface temperatures frequently exceed $40^{\circ} \mathrm{C}$ both urban regions make considerable use of air-conditioning systems.

The control WRF model experiment (hereafter denoted as CTRL) was performed by setting the albedo of the roofs equal to 0.2 , and by setting the fraction of the roofs covered by the solar panels at zero. The remaining $11 \mathrm{WRF}$ model sensitivity experiments correspond to different coverage rates of both roofing technologies, considered individually or jointly (Table 1 contains the complete list of WRF model experiments). For example, the WRF model experiment hereafter denoted as ALB0.75 represents a hypothetical situation where $75 \%$ of each roof is covered with highly reflective membranes [we characterized highly reflective surfaces with an albedo equal to 0.8 (Oleson et al. 2010; Scherba et al. 2011)]. Similarly, the WRF model simulation denoted as FPV0.5 describes a hypothetical situation where $50 \%$ of each roof is covered with solar photovoltaic panels. Finally, the WRF model experiment henceforth denoted as FPV0.75_ALB0.25 represents a hypothetical hybrid situation where 
Table 1 Complete list of WRF model experiments

\begin{tabular}{lcc}
\hline WRF model experiments & $\begin{array}{l}\text { Fraction (\%) of the roofs covered } \\
\text { with highly reflective membranes }\end{array}$ & $\begin{array}{l}\text { Fraction (\%) of the roofs covered } \\
\text { with solar photovoltaic panels }\end{array}$ \\
\hline CTRL & 0 & 0 \\
ALB0.25 & 25 & 0 \\
ALB0.5 & 50 & 0 \\
ALB0.75 & 75 & 0 \\
ALB1.0 & 100 & 0 \\
FPV0.25 & 0 & 25 \\
FPV0.5 & 0 & 50 \\
FPV0.75 & 0 & 75 \\
FPV1.0 & 0 & 100 \\
FPV0.25_ALB0.75 & 75 & 25 \\
FPV0.5_ALB0.5 & 50 & 50 \\
FPV0.75_ALB0.25 & 25 & 75 \\
\hline
\end{tabular}

$75 \%$ of each roof is covered with solar panels and the remaining $25 \%$ is covered with highly reflective membranes. All WRF model experiments that involved solar photovoltaic arrays were conducted by setting the albedo, emissivity, and conversion efficiency of the solar panels equal to $0.11,0.93$, and 0.14 , respectively, which represent typical values for contemporary solar panels technology (e.g., Taha 2013; Masson et al. 2014)

\section{Results and Discussion}

Here, the WRF model + the (BEP+BEM) system's ability to reproduce the observed diurnal cycle of near-surface variables during the 10-day extreme heat period is evaluated. Figure 2 shows the daily CTRL simulation evolution of near-surface air temperature, wind speed, and wind direction against six urban Arizona Meteorological Network weather stations (AZMET; http://ag.arizona.edu/azmet) located within the innermost domain: Buckeye, Mesa, Payson, Phoenix Encanto, Phoenix Greenway, and Tucson. The WRF model preprocessing system at 1-km spatial resolution classified all six stations as urban. The WRF model's hourly output frequency was averaged over all six stations (considering the nearest grid point to station location) and compared with the corresponding averaged observations. Results show that the CTRL experiment slightly overestimated near-surface wind speed, but captured reasonably well the daily evolution of near-surface wind direction and 2-m air temperature, including maximum and minimum temperatures, during the extreme heat event. This notable agreement provides confidence in assessing regional impacts of large-scale cool roof and rooftop solar photovoltaic deployment.

\subsection{Regional Impacts on Near-Surface Air Temperature}

Here, summertime regional effects of cool roof and rooftop solar photovoltaic deployment on near-surface air temperature are analyzed. Figure 3a-d $\left[T_{2}\right.$ (ALB1.0) $-T_{2}$ (CTRL) $]$ illustrates the greater daytime (hereafter understood as the time interval from 0700 to 1900 local time unless specified otherwise) than nighttime (hereafter understood as the time 
(a)

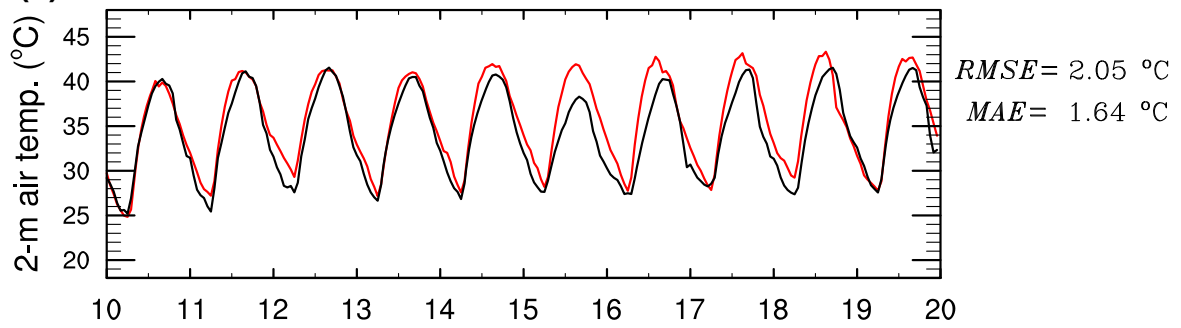

(b)

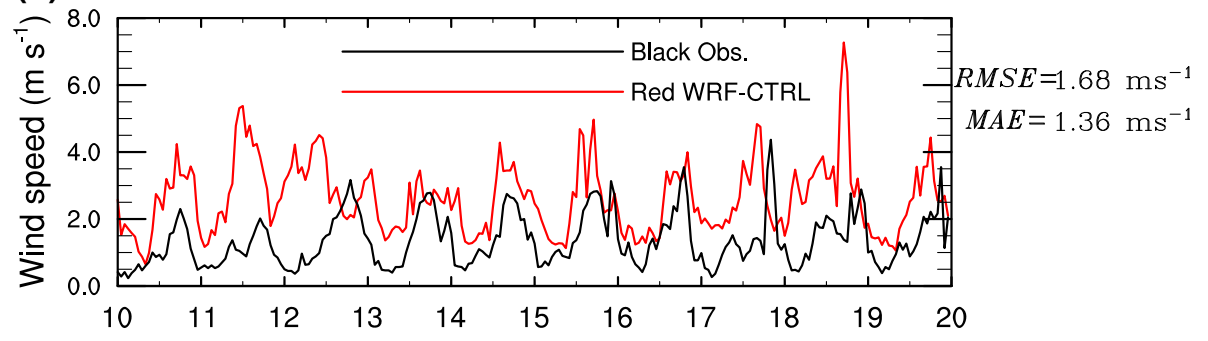

(c)

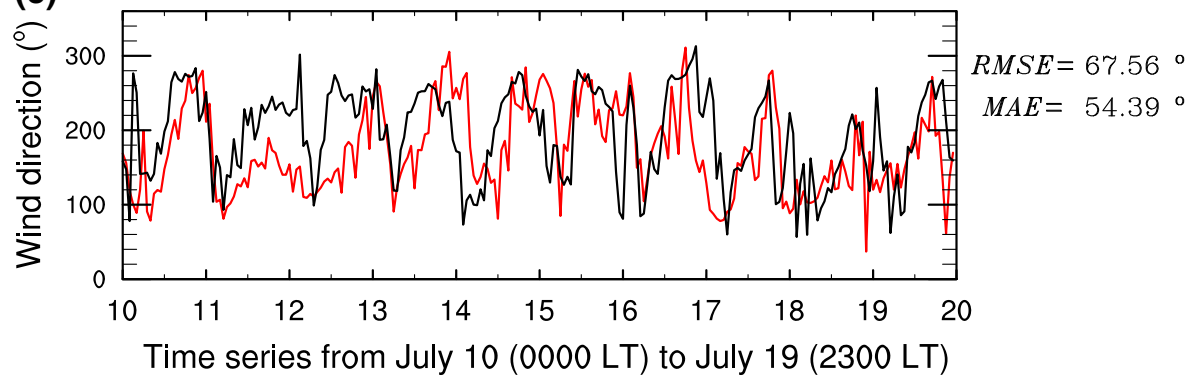

Fig. 2 a Time series of observed (black curve) and CTRL-modelled (red curve) 2-m air temperature $\left({ }^{\circ} \mathrm{C}\right.$ ) averaged over all six AZMET urban stations (Buckeye, Mesa, Payson, Phoenix Encanto, Phoenix Greenway, and Tucson) during the 10-day extreme heat period in July 2009. b Same as in (a) but for the 10-m wind speed $\left(\mathrm{m} \mathrm{s}^{-1}\right)$. (c) Same as in (a) but for the 10-m wind direction $\left(^{\circ}\right)$. Root-mean-square errors $(R M S E)$ and mean absolute errors $(M A E)$ are also indicated

interval from 2000 to 0600 local time unless specified otherwise) cooling effect due to maximum coverage rate of cool roofs. For this maximum coverage rate scenario, cool roofs lowered near-surface temperatures by $0.4-0.8^{\circ} \mathrm{C}$ during the daytime, and rooftop solar panels $T_{2}$ (FPV1.0) $-T_{2}$ (CTRL) lowered near-surface temperatures (Fig. 3e-h) by $0.2-0.4^{\circ} \mathrm{C}$ (i.e., the daytime cooling for solar panels was roughly half of the daytime cooling associated with cool roofs). On the other hand, solar panels generally lowered near-surface temperatures by $0.4-0.8^{\circ} \mathrm{C}$ during the night, directly combating the warming effects associated with the nocturnal UHI. Nighttime cooling associated with cool roofs was less by comparison, generally ranging between 0.1 and $0.4^{\circ} \mathrm{C}$ (i.e., the nighttime cooling for solar panels was roughly twice as large as the nighttime cooling associated with cool roofs)

The behaviour just described is evident for less than maximum coverage rates as well. Figure S1 (a-d) (in Supplementary material) shows the mean impacts for a high large-scale deployment scenario of cool roofs $T_{2}(\mathrm{ALB} 0.75)-T_{2}(\mathrm{CTRL})$. During the day, cool roofs 

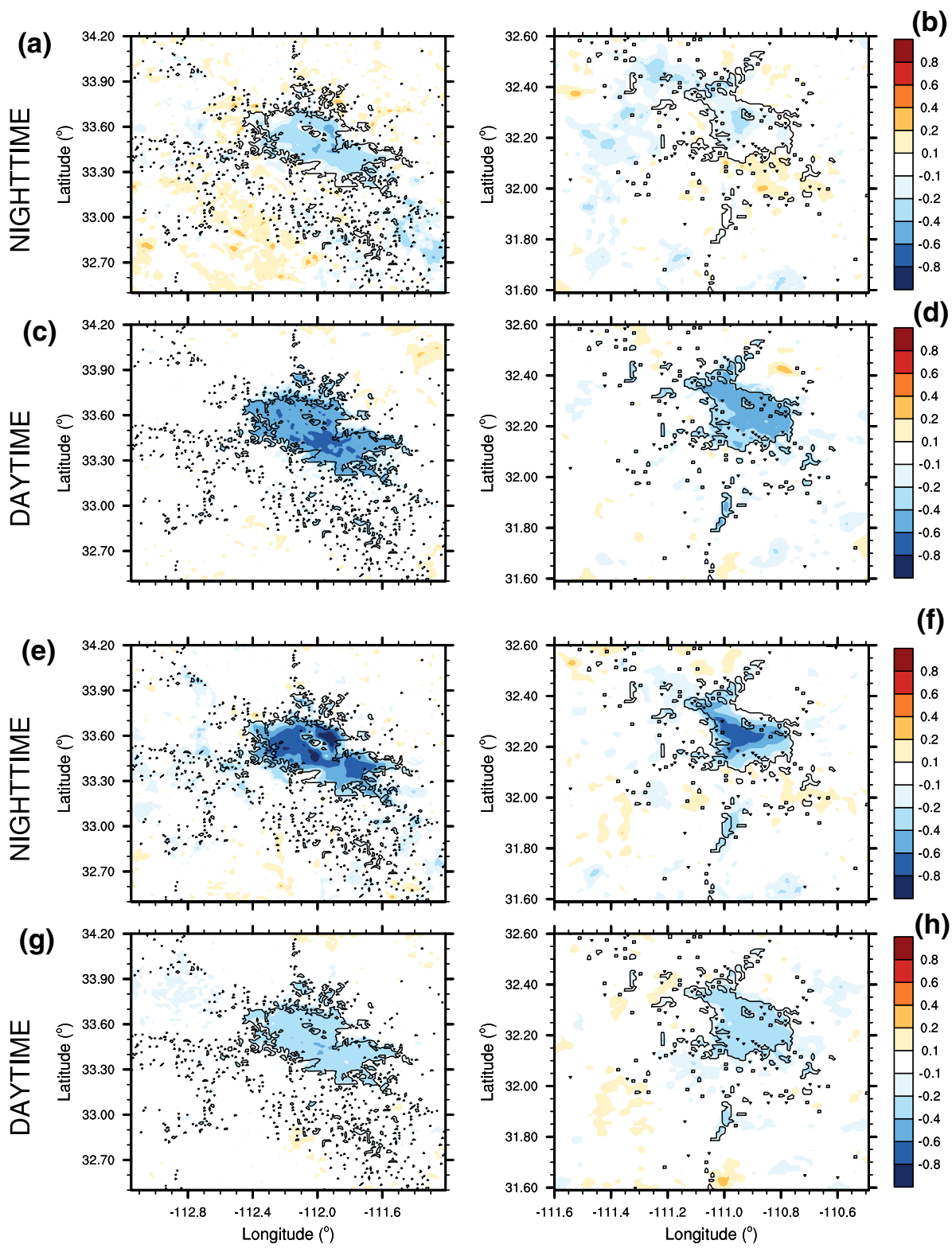

Fig. 3 Modelled mean 2-m air temperature differences $T_{2}$ (ALB1.0) $-T_{2}$ (CTRL) averaged for the entire 10day extreme heat period in July 2009 during nighttime hours (a, b) and during daytime hours (c, d) for Phoenix (left) and Tucson (right) regions, respectively. $\mathbf{e}-\mathbf{h}$ Same as in (a-d) but for $T_{2}$ (FPV1.0) $-T_{2}(\mathrm{CTRL})$. Urban land use is bounded by black contours 
reduced the near-surface air temperature up to $0.5^{\circ} \mathrm{C}$ for some central areas of Phoenix and Tucson. However, during the night, the cooling was less significant and typically ranged from 0.1 to $0.2{ }^{\circ} \mathrm{C}$. These results concur with those presented in Scherba et al. (2011) and recent high-resolution modelling simulations for California (Georgescu 2015) reporting that typical black and white roofs have similar skin temperature during the night but extremely different during the day (black roofs are warmer).

Figure S1 (e-h) shows the mean impacts on near-surface air temperature for a high largescale deployment scenario of rooftop solar photovoltaic panels $T_{2}$ (FPV0.75) $-T_{2}$ (CTRL). During the day, cooling of $0.1-0.3^{\circ} \mathrm{C}$ extends throughout both metropolitan areas with peak cooling for both regions approaching $0.4^{\circ} \mathrm{C}$. During the night, most urban areas experienced slight cooling ranging between 0.1 and $0.3^{\circ} \mathrm{C}$ in Phoenix, and between 0.1 and $0.4{ }^{\circ} \mathrm{C}$ in Tucson. These results seem to indicate that cool roofs are more effective at cooling than rooftop solar panels during the day, but not during the night.

Reduced deployment (coverage rates of 25 or $50 \%$ ) of cool roofs and rooftop solar photovoltaic panels did not reveal new phenomena (the $50 \%$ case is discussed below and is shown as Fig. S2 in the supplementary material). Cool roofs reduced near-surface temperatures $0.2-0.4^{\circ} \mathrm{C}$ during the day while the reduction by solar photovoltaic panels ranged between 0.1 and $0.3^{\circ} \mathrm{C}$. During the night, both roofing technologies did not demonstrate a significant impact for Phoenix but displayed cooling for Tucson (ranging between 0.1 and $0.3^{\circ} \mathrm{C}$ ), which was stronger for the scenario with solar panels (up to $0.4{ }^{\circ} \mathrm{C}$ ).

Figure 4 shows the diurnal cycle of near-surface air temperature differences (we subtracted the CTRL experiment from each WRF sensitivity experiment) averaged across the Phoenix metropolitan area for all coverage rates (including the hybrid scenarios) of cool roof and rooftop solar photovoltaic deployment (results for the Tucson metropolitan area are shown as Fig. S3 in the supplementary material). During the day, deployment of cool roofs is more effective at cooling the near-surface environment than rooftop solar photovoltaic panels. However, during the night, solar panels are more effective at reducing the UHI intensity.

Finally, we estimated the robustness of our simulation results by calculating the number of times (showed as a frequency in \%) that near-surface air temperature difference $\left({ }^{\circ} \mathrm{C}\right.$ ) was in a particular range, by considering independently each urban grid cell and each hour during the entire 10-day extreme heat period. Figures 5, 6 and 7 show results for all coverage rates (including the hybrid scenarios) compared to the CTRL experiment. Near-surface cooling for the most aggressive scenarios $T_{2}$ (ALB1.0) $-T_{2}$ (CTRL), $T_{2}$ (FPV1.0) $-T_{2}$ (CTRL), and $T_{2}$ (FPV0.25_ALB0.75) $-T_{2}$ (CTRL) (Figs. 5d, 6d, and 7c, respectively) occurred 71, 69, and $71 \%$ of the time, providing confidence that simulated averaged impacts are a robust consequence of cool roof and rooftop solar photovoltaic deployment. On the other hand, results for the least aggressive scenarios $T_{2}$ (ALB0.25) $-T_{2}$ (CTRL), and $T_{2}(\mathrm{FPV} 0.25)-T_{2}$ (CTRL) (Figs. 5a and 6a, respectively) illustrate a reduced probability of cooling. For these minimum coverage rate scenarios cooling was simulated for 56 and $58 \%$ of the time for solar panels and cool roof technologies, respectively, illustrating reduced confidence that these strategies can capably reduce near-surface temperatures.

\subsection{Regional Impacts on Cooling Energy Demand}

We next discuss summertime regional impacts of cool roof and rooftop solar photovoltaic deployment on cooling energy demand. Figure 8 shows the diurnal cycle of citywide airconditioning electricity consumption (in $\mathrm{MW} \mathrm{km} \mathrm{km}^{-2}$ of urban land) for all coverage rates of cool roof and rooftop solar photovoltaic deployment for both Phoenix and Tucson metropolitan areas. During July 2009, the observed monthly mean maximum near-surface air 


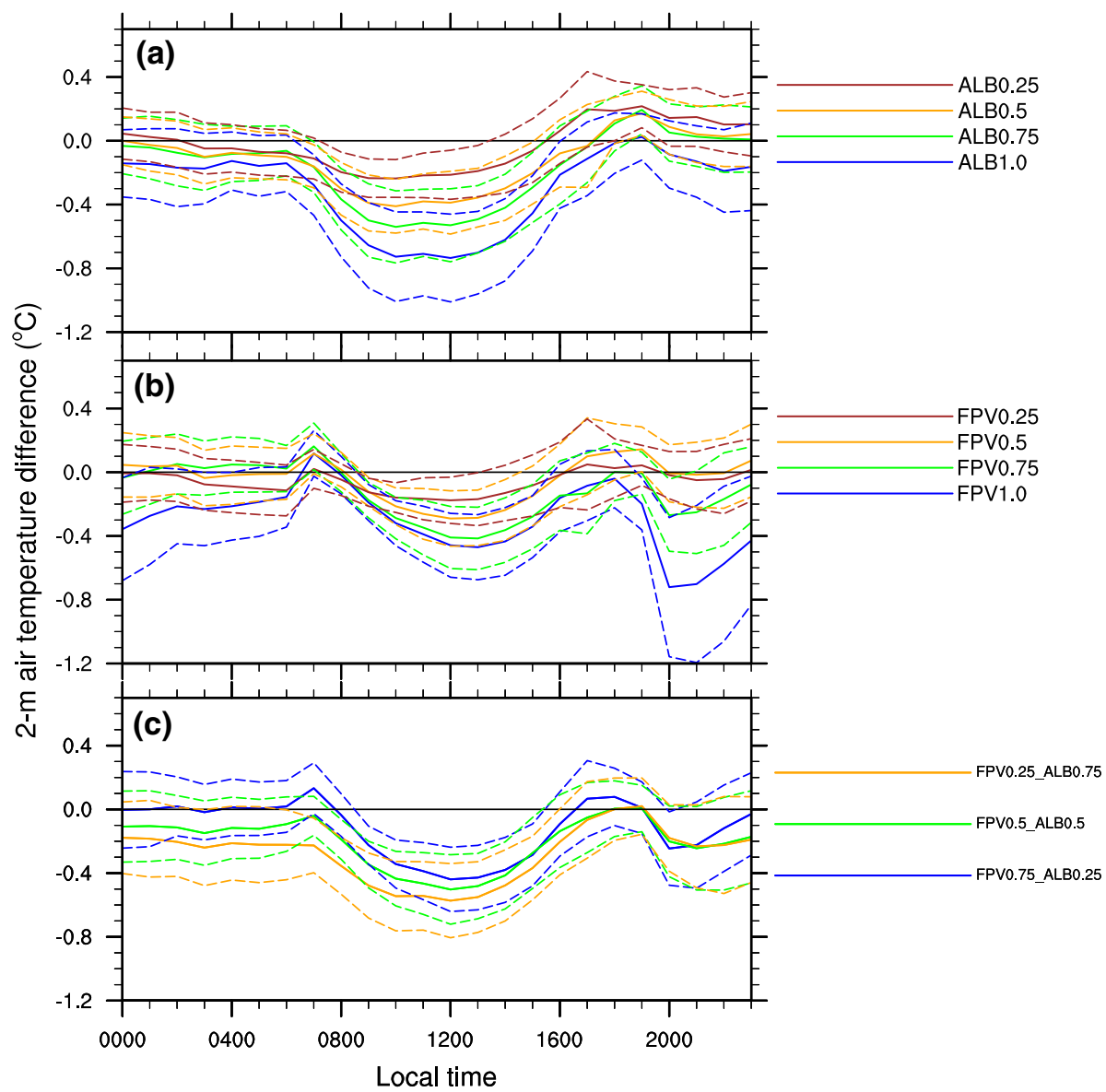

Fig. 4 a-c Diurnal cycle of modelled 2-m air temperature differences (we subtracted the CTRL simulation from each WRF model experiment) averaged for the entire 10-day extreme heat period in July 2009 and across the Phoenix metropolitan area for all coverage rates of cool roof deployment. $\mathbf{b}$ Same as in (a) but for all coverage rates of rooftop solar photovoltaic deployment. c Same as in (a) but for all the hybrid WRF model experiments. Dashed lines represent \pm one standard deviation relative to mean difference showed by the solid curves

temperature was $42.8^{\circ} \mathrm{C}$ for Phoenix and $38.3^{\circ} \mathrm{C}$ for Tucson (http://ag.arizona.edu/azmet/), which explains why local cooling energy demands $\left(\mathrm{MW} \mathrm{km}^{-2}\right)$ were greater for the Phoenix metropolitan area. Rooftop solar photovoltaic panels (Fig. 8a) reduced air-conditioning electricity consumption during the day but not during the night. In fact, during the night, solar panels increased the cooling energy demand. For example, for the Phoenix metropolitan area, FPV1.0 experiment decreased the maximum peak demand by $23 \%$ but increased the minimum demand (that normally happens shortly after sunrise) by $25 \%$ compared to the CTRL experiment. A roof partially covered with solar panels receives less incoming solar radiation than a typical roof and, consequently, a smaller amount of heat is diffused into the building. However, during the night, solar panels can reduce the radiative cooling of the roof and increase the nocturnal building-cooling load. Dominguez et al. (2011) reported this occurrence by means of observations. During the night, the interior ceiling surface temper- 

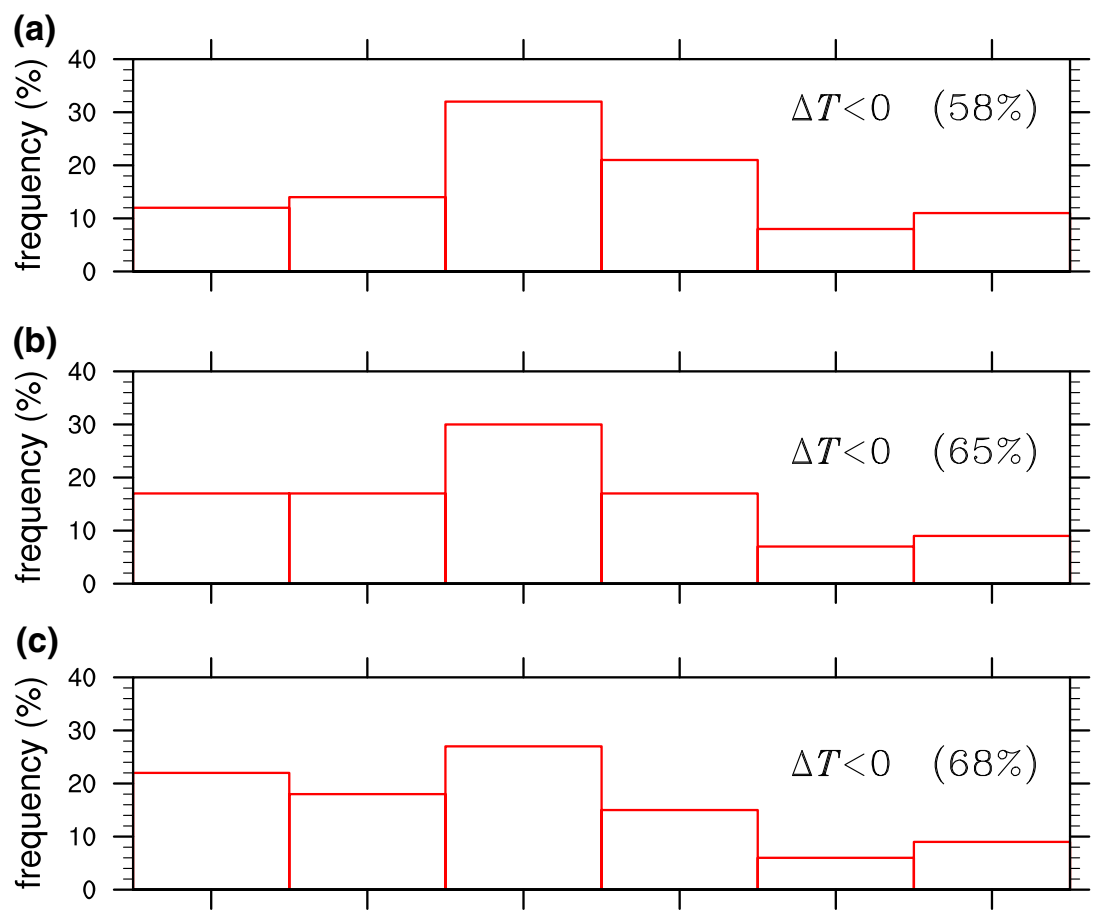

(d)

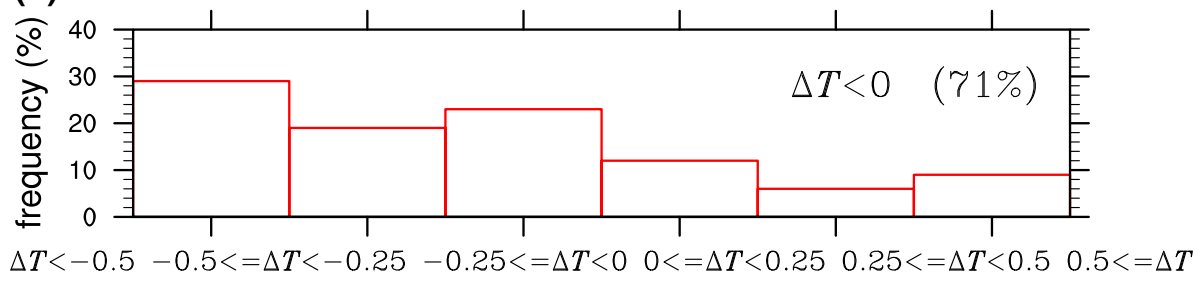

Fig. 5 a Bar charts depict the number of times (showed as a frequency in \%) that the modelled 2-m air temperature difference $\left[\Delta T=T_{2}(\mathrm{ALB} 0.25)-T_{2}(\mathrm{CTRL})\right]\left({ }^{\circ} \mathrm{C}\right)$ was in a particular range considering independently each urban grid cell and each hour during the entire 10-day extreme heat period. b-d Same as in (a) but for $T_{2}$ (ALB0.5) $-T_{2}$ (CTRL), $T_{2}$ (ALB0.75) $-T_{2}$ (CTRL), and $T_{2}$ (ALB1.0) $-T_{2}$ (CTRL), respectively. $\Delta T<0(\mathrm{XX} \%)$ indicates the number of times (in \%) that the modelled 2-m air temperature difference was negative

ature under a roof partially covered with solar panels was greater than the interior ceiling surface temperature of the same roof without solar panels.

Regional impacts of cool roof deployment (on cooling energy demand) are presented in Fig. 8b. Cool roofs reduced heat transfer into the buildings across the diurnal cycle although most of this decrease occurs during the day. During the night, black and white roofs maintain a similar skin temperature and building-cooling load differences are less significant. For example, the ALB1.0 experiment decreased the maximum peak demand by $14 \%$ and the minimum demand by $10 \%$ compared to the CTRL experiment for the Phoenix metropolitan area.

As a final point, we computed (see first two columns of Table 2) the degree of urban-wide cooling energy demand savings across the diurnal cycle, for each scenario and metropolitan area compared to the CTRL experiment. Results show that any coverage rate of large-scale 


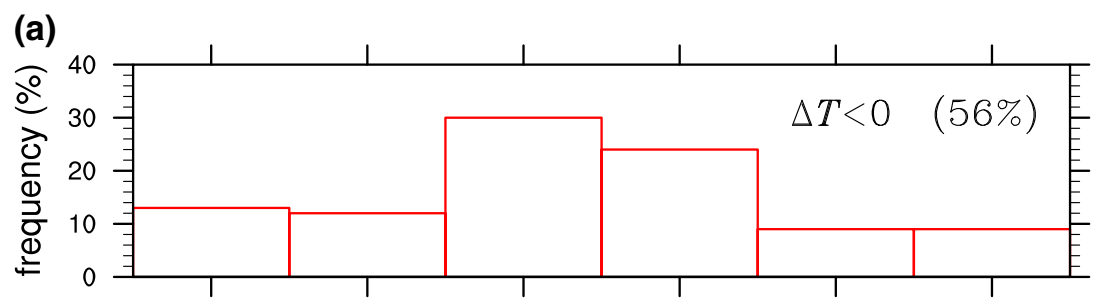

(b)
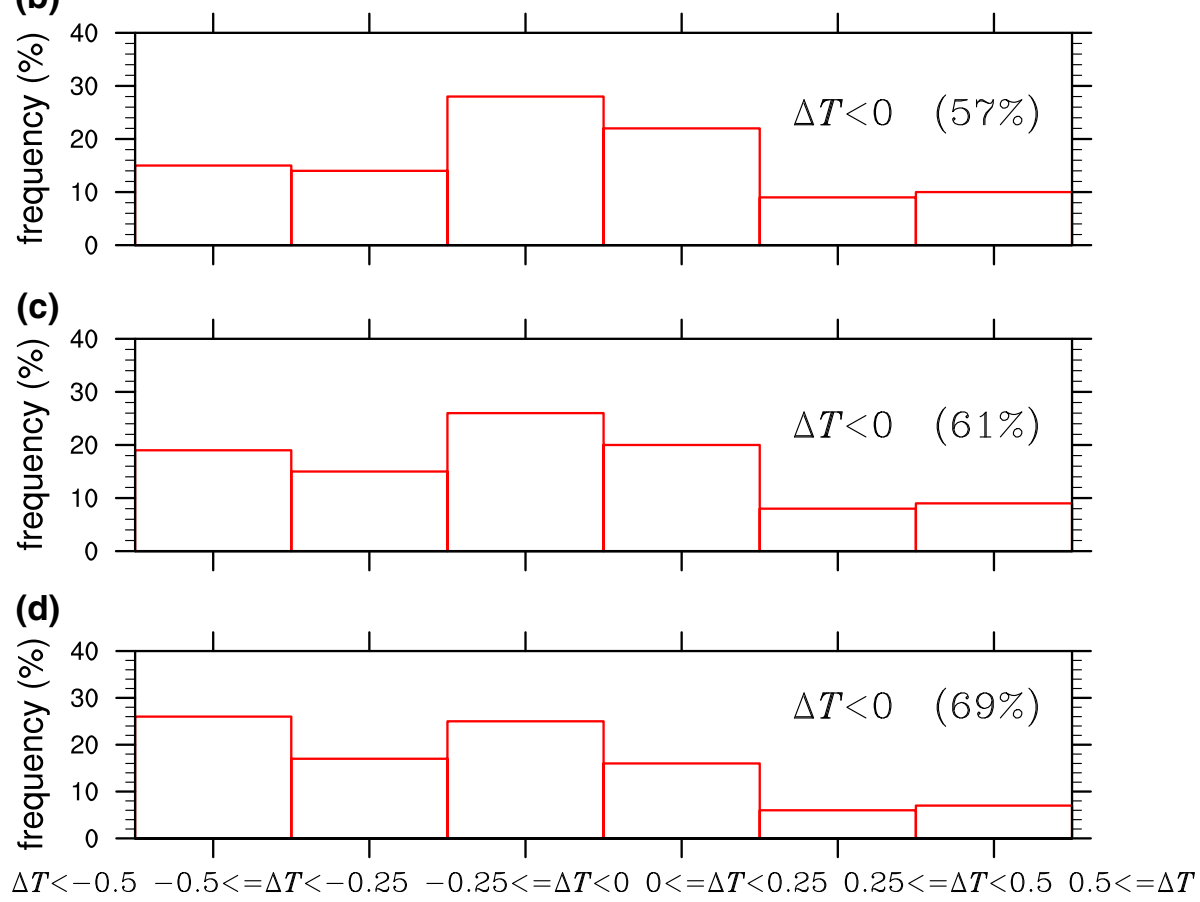

Fig. 6 a Bar charts depict the number of times (showed as a frequency in \%) that the modelled 2-m air temperature difference $\left[\Delta T=T_{2}(\mathrm{FPV} 0.25)-T_{2}(\mathrm{CTRL})\right]\left({ }^{\circ} \mathrm{C}\right)$ was in a particular range considering independently each urban grid cell and each hour during the entire 10-day extreme heat period. b-d Same as in (a) but for $T_{2}$ (FPV0.5) $-T_{2}$ (CTRL), $T_{2}$ (FPV0.75) $-T_{2}$ (CTRL), and $T_{2}$ (FPV1.0) $-T_{2}$ (CTRL), respectively. $\Delta T<0$ $(\mathrm{XX} \%)$ indicates the number of times (in \%) that the modelled 2-m air temperature difference was negative

cool-roof deployment reduced considerably cooling energy demand, with a maximum saving of 13-14 \% computed for the most aggressive coverage scenario. On the other hand, largescale deployment of rooftop solar photovoltaic panels only produced a clear saving when the coverage rate was greater than $50 \%$. It is important to keep in mind that these computed savings do not account for the additional savings derived from electricity production from solar panels. Rooftop solar panels combined with cool roofs (i.e., hybrid scenarios) reduced cooling energy demand for all coverage rates of both roofing technologies, with the maximum saving computed for the FPV0.25_ALB0.75 scenario.

Finally, to provide guidance on the potential consequences for air quality associated with the implementation of these roofing technologies, we calculated changes in planetary boundary-layer (PBL) depth for each scenario and metropolitan area compared to the CTRL experiment (see last two columns in Table 2). It is evident that any coverage rate of large-scale 

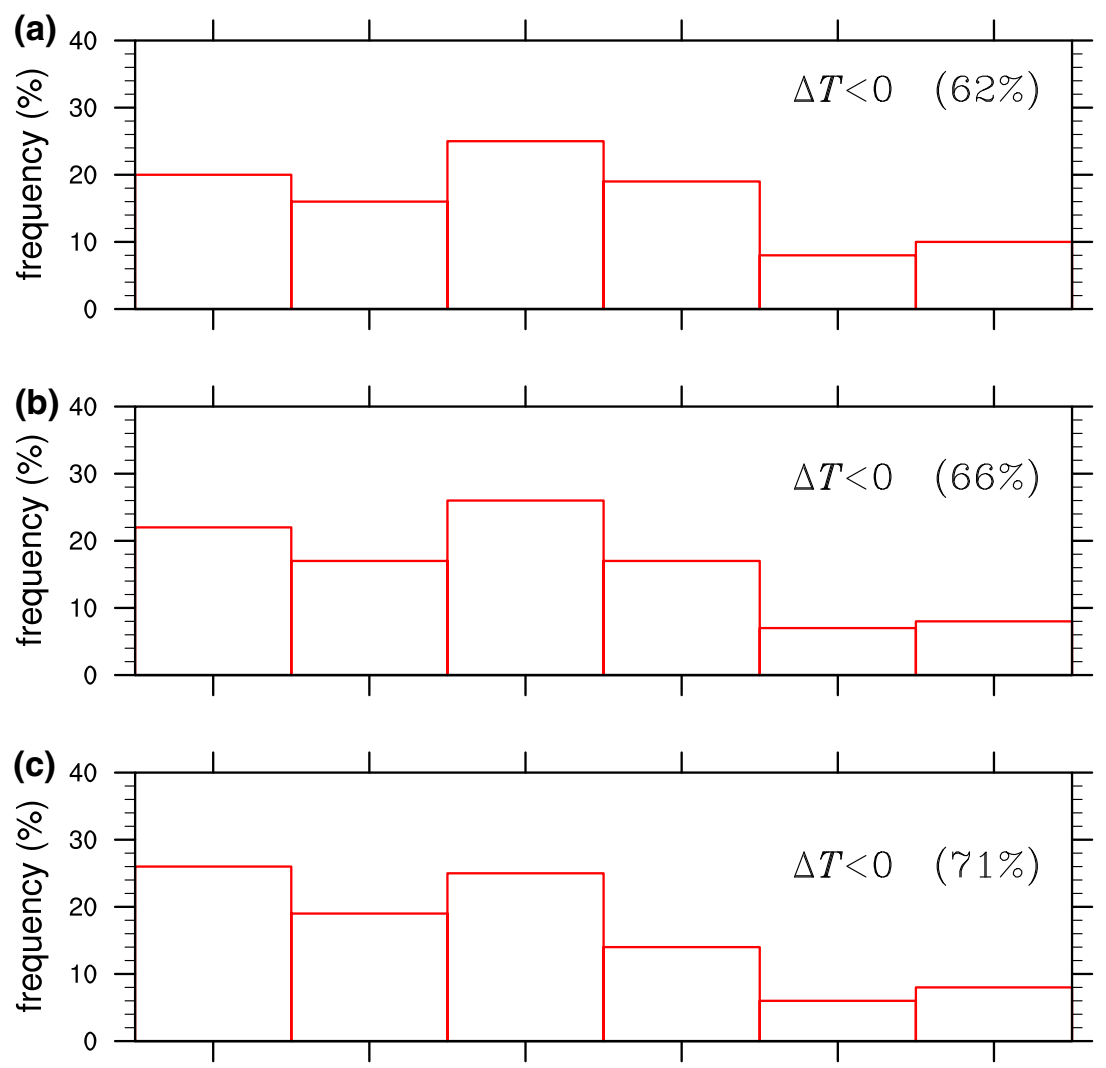

$\Delta T<-0.5-0.5<=\Delta T<-0.25 \quad-0.25<=\Delta T<0 \quad 0<=\Delta T<0.25 \quad 0.25<=\Delta T<0.5 \quad 0.5<=\Delta T$

Fig. 7 a Bar charts depict the number of times (showed as a frequency in \%) that the modelled 2-m air temperature difference $\left[\Delta T=T_{2}\left(\mathrm{FPV} 0.75 \_\mathrm{ALB} 0.25\right)-T_{2}(\mathrm{CTRL})\right]\left({ }^{\circ} \mathrm{C}\right)$ was in a particular range considering independently each urban grid cell and each hour during the entire 10-day extreme heat period. b, c Same as in (a) but for $T_{2}$ (FPV0.5_ALB0.5) $-T_{2}$ (CTRL), and $T_{2}$ (FPV0.25_ALB0.75) $-T_{2}$ (CTRL), respectively. $\Delta T<0(\mathrm{XX} \%)$ indicates the number of times (in \%) that the modelled 2-m air temperature difference was negative

cool roof and rooftop solar photovoltaic deployment reduce the convective PBL height, and the maximum reduction (between $\approx 150$ to $225 \mathrm{~m}$ ) was computed for the most aggressive scenarios (i.e., ALB1.0, FPV1.0, and FPV0.25_ALB0.75 experiments). Additionally, we analyzed (for these previous WRF model experiments) the spatial distribution of PBL height reduction averaged for the entire 10-day extreme heat period. Results show that the convective PBL depth was reduced over both Phoenix and Tucson metropolitan areas (Fig. 9), which reveals a reduced capability for the lower atmosphere to effectively mix pollutants vertically, with potential implications for air quality (e.g., Georgescu 2015; Li et al. 2014 and 2015). However, Fig. 9 also illustrates complex and variable spatial gradients in areas located outside the urban limits. We believe these structures are dependent on horizontal grid size because similar effects have been documented in previous work (e.g., Ching et al. 2014), but an analysis to determine their credibility requires future research and is beyond the scope of the present work. 

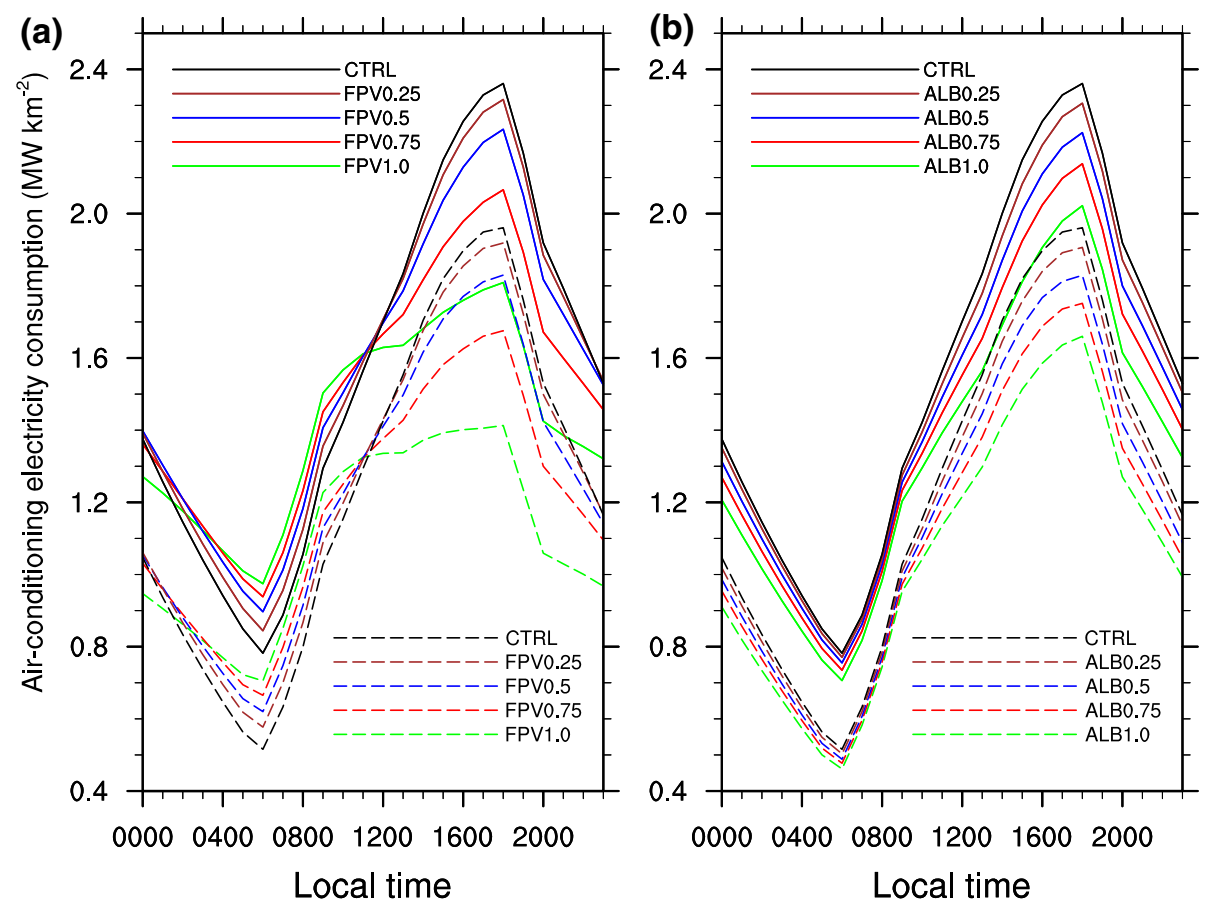

Fig. 8 a Diurnal cycle of modelled air-conditioning electricity consumption (MW km ${ }^{-2}$ of urban land) averaged for the entire 10-day extreme heat period in July 2009 and across the Phoenix (continuous curves) and Tucson (dashed curves) metropolitan areas for all coverage rates of rooftop solar photovoltaic deployment. b Same as in (a) but for all coverage rates of cool roof deployment

Table 2 Cooling energy savings across the diurnal cycle (\%) and planetary boundary-layer depth reduction ( $\delta h)$ (compared to the CTRL experiment) computed for both Phoenix (PHX) and Tucson (TUC) metropolitan areas

\begin{tabular}{lcccc}
\hline WRF model experiments & $\begin{array}{l}\text { Cooling } \\
\text { energy savings } \\
(\%) \text { PHX }\end{array}$ & $\begin{array}{l}\text { Cooling } \\
\text { energy savings } \\
(\%) \text { TUC }\end{array}$ & & \\
\hline ALB0.25 & $2.2 \pm 0.4$ & $2.8 \pm 0.6$ & $-34.7 \pm 73.1$ & $-23.9 \pm 81.9$ \\
ALB0.5 & $5.2 \pm 0.4$ & $6.3 \pm 0.9$ & $-98.5 \pm 81.5$ & $-61.4 \pm 83.7$ \\
ALB0.75 & $8.5 \pm 0.7$ & $9.8 \pm 1.3$ & $-149.5 \pm 91.6$ & $-114.0 \pm 106.5$ \\
ALB1.0 & $13.1 \pm 1.0$ & $14.2 \pm 1.6$ & $-225.1 \pm 109.2$ & $-156.3 \pm 89.6$ \\
FPV0.25 & $-0.7 \pm 0.6$ & $-0.8 \pm 0.9$ & $-43.8 \pm 72.8$ & $-35.2 \pm 77.0$ \\
FPV0.5 & $-0.1 \pm 0.9$ & $0.7 \pm 1.1$ & $-78.8 \pm 78.0$ & $-43.5 \pm 86.0$ \\
FPV0.75 & $3.0 \pm 1.0$ & $4.0 \pm 1.6$ & $-135.7 \pm 88.6$ & $-81.8 \pm 88.3$ \\
FPV1.0 & $8.7 \pm 1.0$ & $11.0 \pm 2.3$ & $-155.0 \pm 88.7$ & $-85.9 \pm 75.8$ \\
FPV0.25_ALB0.75 & $7.3 \pm 0.6$ & $8.5 \pm 1.4$ & $-171.1 \pm 96.8$ & $-122.3 \pm 88.8$ \\
FPV0.5_ALB0.5 & $4.5 \pm 0.8$ & $5.7 \pm 1.4$ & $-134.6 \pm 86.0$ & $-89.6 \pm 84.0$ \\
FPV0.75_ALB0.25 & $4.3 \pm 1.1$ & $6.4 \pm 1.7$ & $-131.4 \pm 88.0$ & $-88.7 \pm 100.8$
\end{tabular}


(a)

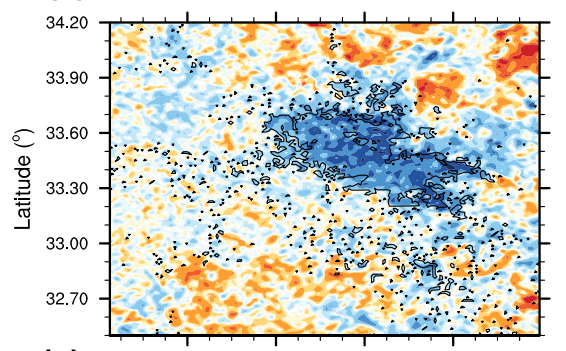

\section{(c)}

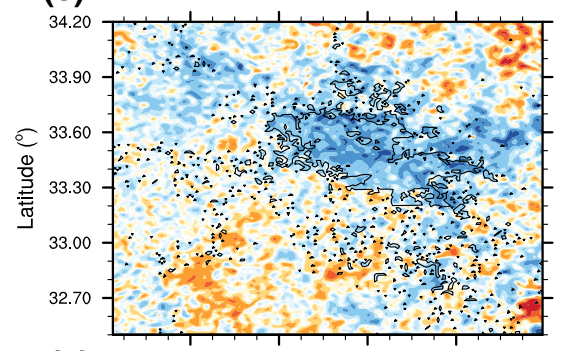

\section{(e)}

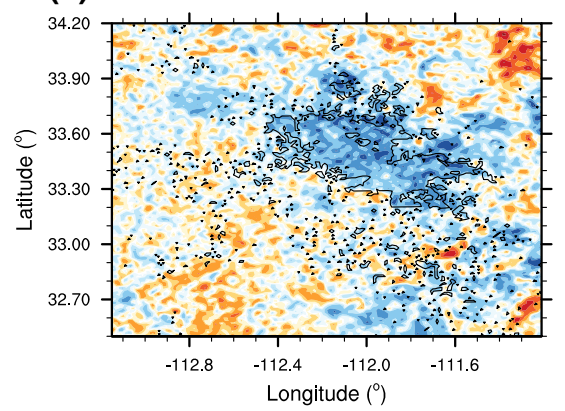

(b)

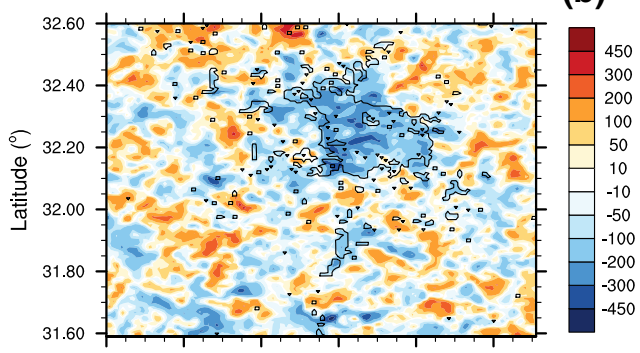

(d)

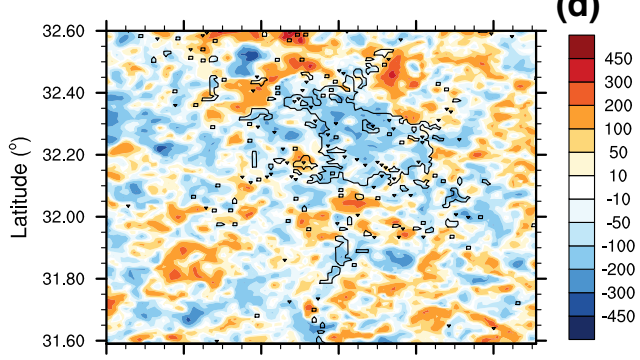

(f)

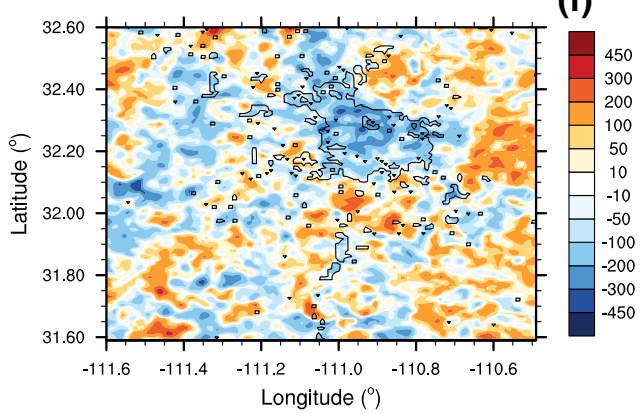

Fig. 9 a, b Spatial distribution of the modelled PBL height reduction $\delta h$ (ALB1.0 - CTRL) (m) averaged for the entire 10-day extreme heat period in July 2009 for Phoenix (left) and Tucson (right) metropolitan areas. c, d Same as in (a, b) but for $\delta h($ FPV1 $1.0-$ CTRL). e, f Same as in (a, b) but for $\delta h($ FPV0.25_ALB0.75 - CTRL). Urban land use is bounded by black contours

\section{Summary and Conclusions}

Here we assess summertime regional impacts of large-scale cool roof and rooftop solar photovoltaic deployment on near-surface air temperature and cooling energy demand using a fully coupled modelling system composed of a regional climate model and a multilayer building energy model. Our emphasis on hot semi-arid urban environments is justified given, (1) significant summertime cooling demands for these regions, and (2) anticipated greater urban growth rates within arid and semi-arid areas relative to other ecological zones in future decades. There is therefore considerable interest in the design and implementation of sustainable strategies that reduce the direct impact of urban expansion (e.g., the UHI) and simultaneously reduce emissions of long-lived greenhouse gases.

Our results demonstrate that the deployment of cool roofs and rooftop solar photovoltaic panels reduce near-surface air temperature and cooling energy demand at the scale of the 
metropolitan area. During the day, cool roofs are more effective at cooling than rooftop solar panels, but solar panels are more efficient at reducing the nocturnal UHI magnitude (i.e., horizontal 2-m air temperature difference), and therefore more directly combat effects associated with urban development. For the most aggressive coverage rate deployment, cool roofs (rooftop solar photovoltaic panels) lowered mean daytime (nighttime) near-surface air temperature up to $0.8^{\circ} \mathrm{C}$. On the other hand, cool roofs are more effective than rooftop solar panels at reducing daily cooling energy demand because solar panels increase nocturnal building-cooling loads. When the maximum coverage rate was considered, the implementation of both roofing technologies reduced daily citywide cooling energy demand by 13-14 \% for the case of cool roofs, and by 8-11\% for the case of rooftop solar photovoltaic panels.

Originally, solar photovoltaic panels were developed to diminish dependence on fossil fuels aimed at mitigation of global warming, rather than to combat the UHI. However, we show here that extensive deployment of rooftop solar photovoltaic panels can be considered as an additional mitigation strategy. In addition to electricity generation, continued technological improvement via enhancement of solar conversion efficiencies can provide further benefits for widespread deployment of solar panels. Although we demonstrate that both roofing technologies (cool roofs and rooftop solar photovoltaic panels) are an effective way to reduce urban temperatures and to alleviate UHI effects, potential implications for air quality associated with the reduction of PBL height requires additional investigation to more comprehensively examine the merit of differing strategies. As a final point, we conclude by pointing out that these results have been obtained during a summertime period and should not be extrapolated to other seasons (e.g., winter) or to other cities in non-semi arid biomes. Morphological differences among various urban areas (e.g., cities with different building plan area fraction, different building sizes, etc) are also important considerations that warrant assessment.

Acknowledgments This work has been funded by NSF Grant DMS 1419593 and USDA NIFA Grant 201567003-23508.

Open Access This article is distributed under the terms of the Creative Commons Attribution 4.0 International License (http://creativecommons.org/licenses/by/4.0/), which permits unrestricted use, distribution, and reproduction in any medium, provided you give appropriate credit to the original author(s) and the source, provide a link to the Creative Commons license, and indicate if changes were made.

\section{References}

Akbari H, Menon S, Rosenfeld A (2009) Global cooling: increasing world-wide urban albedos to offset $\mathrm{CO}_{2}$. Clim Change 94:275-286

Brazel A, Selover N, Vose R, Heisler G (2000) The tale of two climates-Baltimore and Phoenix urban LTER sites. Clim Res 15:123-135

Bretz SE, Akbari H (1997) Long-term performance of high-albedo roof coatings. Energy Build 25:159-167

Burian SJ, Velugubantla SP, Brown MJ (2002) Morphological analyses using 3D building databases: Phoenix, Arizona, LA-UR-02-6726. Los Alamos National, Laboratory, pp 1-65

Chen F, Dudhia J (2001) Coupling and advanced land-surface hydrology model with the Penn State-NCAR MM5 Modeling System. Part I: Model implementation and sensitivity. Mon Weather Rev 129:569-585

Ching J, Rotunno R, Lemone M, Martilli A, Kosovic B, Jimenez PA, Dudhia J (2014) Convectively induced secondary circulations in fine-grid mesoscale numerical weather prediction models. Mon Weather Rev 142:3284-3302

Chow WTL, Salamanca F, Georgescu M, Mahalov A, Milne JM, Ruddell BL (2014) A multi-method and multi-scale approach for estimating city-wide anthropogenic heat fluxes. Atmos Environ 99:64-76

Clarke JA, Yaneske PP, Pinney AA (1991) The harmonization of thermal properties of building materials. Tech. Note 91/6. BEPAC, 87 pp 
Cotana F, Rossi F, Filipponi M, Coccia V, Pisello AL, Bonamente E, Petrozzi A, Cavalaglio G (2014) Albedo control as an effective strategy to tackle Global Warming: a case study. Appl Energy 130:641-647

Dominguez A, Kleissl J, Luvall JC (2011) Effects of solar photovoltaic panels on roof heat transfer. Solar Energy 85:2244-2255

Ek MB, Mitchell KE, Lin Y, Rogers E, Grunmann P, Koren V, Gayno G, Tarpley JD (2003) Implementation of Noah land surface model advances in the National Centers for Environmental Prediction operational mesoscale Eta model. J Geophys Res Atmos 108(D22):8851. doi:10.1029/2002JD003296

Fry J et al (2011) Completion of the 2006 National Land Cover Database for the conterminous United States. Photogramm Eng Remote Sensing 77:858-864

Georgescu M (2015) Challenges associated with adaptation to future urban expansion. J Clim 28:2544-2563. doi:10.1175/JCLI-D-14-00290.1

Georgescu M, Moustaoui M, Mahalov A, Dudhia J (2011) An alternative explanation of the semiarid urban area "oasis effect". J Geophys Res Atmos 116:D24113. doi:10.1029/2011JD016720

Georgescu M, Mahalov A, Moustaoui M (2012) Seasonal hydroclimatic impacts of Sun Corridor expansion. Environ Res Lett 7:034026

Georgescu M, Moustaoui M, Mahalov A, Dudhia J (2013) Summer-time climate impacts of projected megapolitan expansion in Arizona. Nat Clim Change 3:37-41

Georgescu M, Morefield PE, Bierwagen BG, Weaver CP (2014) Urban adaptation can roll back warming of emerging megapolitan regions. Proc Natl Acad Sci USA 111:2909-2914. doi:10.1073/pnas.1322280111

Gutierrez E, Gonzalez JE, Martilli A, Bornstein R, Arend M (2015) Simulations of a heat-wave event in New York City using a multilayer urban parameterization. J Appl Meteorol Climatol 54:283-301

Li D, Bou-Zeid E, Oppenheimer M (2014) The effectiveness of cool and green roofs as urban heat island mitigation strategies. Environ Res Lett 9:055002

Li J, Georgescu M, Hyde P, Mahalov A, Moustaoui M (2014) Achieving accurate simulations of urban impacts on ozone at high resolution. Environ Res Lett 9:114019

Li J, Georgescu M, Hyde P, Mahalov A, Moustaoui M (2015) Regional-scale transport of air pollutants: impacts of southern California emissions on Phoenix ground-level ozone concentrations. Atmos Chem Phys 15:9345-9360

Martilli A (2014) An idealized study of city structure, urban climate, energy consumption, and air quality. Urban Clim 10:430-446

Martilli A, Clappier A, Rotach MW (2002) An urban surface exchange parameterization for mesoscale models. Boundary-Layer Meteorol 104:261-304

Masson V, Bonhomme M, Salagnac J-L, Briottet X, Lemonsu A (2014) Solar panels reduce both global warming and urban heat island. Front Environ Sci. doi:10.3389/fenvs.2014.00014

Menon S, Akbari H, Mahanama S, Sednev I, Levinson R (2010) Radiative forcing and temperature response to changes in urban albedos and associated $\mathrm{CO}_{2}$ offsets. Environ Res Lett 5:014005

Millstein D, Menon S (2011) Regional climate consequences of large-scale cool roof and photovoltaic array deployment. Environ Res Lett 6:034001

Oleson KW, Bonan GB, Feddema J (2010) Effects of white roofs on urban temperature in a global climate model. Geophys Res Lett 37:L03701. doi:10.1029/2009GL042194

Salamanca F, Martilli A (2010) A new building energy model coupled with an urban canopy parameterization for urban climate simulations-part II. Validation with one dimension off-line simulations. Theor Appl Climatol 99:345-356

Salamanca F, Krpo A, Martilli A, Clappier A (2010) A new building energy model coupled with an urban canopy parameterization for urban climate simulations-part I. Formulation, verification, and sensitivity analysis of the model. Theor Appl Climatol 99:331-344

Salamanca F, Martilli A, Tewari M, Chen F (2011) A study of the urban boundary layer using different urban parameterizations and high-resolution urban canopy parameters with WRF. J Appl Meteorol Climatol 50:1107-1128

Salamanca F, Tonse S, Menon S, Garg V, Singh KP, Naja M, Fischer ML (2012a) Top-of-atmosphere radiative cooling with white roofs: experimental verification and model-based evaluation. Environ Res Lett 7:044007

Salamanca F, Martilli A, Yague C (2012b) A numerical study of the urban heat island over Madrid during the DESIREX (2008) campaign with WRF and evaluation of simple mitigation strategies. Int J Climatol $32: 2372-2386$

Salamanca F, Georgescu M, Mahalov A, Moustaoui M, Wang M, Svoma BM (2013) Assessing summertime urban air conditioning consumption in a semiarid environment. Environ Res Lett 8:034022

Salamanca F, Georgescu M, Mahalov A, Moustaoui M, Wang M (2014) Anthropogenic heating of the urban environment due to air conditioning. J Geophys Res Atmos 119:5949-5965 
Salamanca F, Georgescu M, Mahalov A, Moustaoui M (2015) Summertime response of temperature and cooling energy demand to urban expansion in a semiarid environment. J Appl Meteorol Climatol 54:17561772. doi:10.1175/JAMC-D-14-0313.1

Scherba A, Sailor DJ, Rosenstiel TN, Wamser CC (2011) Modeling impacts of roof reflectivity, integrated photovoltaic panels and green roof systems on sensible heat flux into the urban environment. Build Environ 46:2542-2551

Skamarock WC, Klemp JB, Dudhia J, Gill DO, Barker DM, Duda MG, Huang X-Y, Wang W, Powers JG (2008) A description of the advanced research WRF version 3, NCAR Tech. Note NCAR/TN-475+STR. National Center for Atmospheric Research, Boulder, p 125

Taha H (2013) The potential for air-temperature impact from large-scale deployment of solar photovoltaic arrays in urban areas. Solar Energy 91:358-367 